\title{
Mathematical modeling of tech-related real-world problems for secondary school-level mathematics
}

\author{
Zehavit Kohen $^{1}$ (D) Doron Orenstein ${ }^{1}$
}

Accepted: 22 December 2020 / Published online: 26 January 2021

(C) The Author(s) 2021

\begin{abstract}
The use of authentic real-world problems that reflect the applied nature of mathematics is not prevalent in formal secondary school settings. In this study, we explore the interface between workplace mathematics, particularly tech-related real-world (TRW) problems, and school mathematics, through the explication of mathematical modeling. The research questions are (1) in which tech domains can real-world problems be identified that can be addressed using mathematical modeling for the secondary school level? (2) Which methods do engineers use to simplify tech-related problems for non-experts in their field? (3) In which areas in the secondary mathematics curriculum can TRW problems be mapped? We present a three-phase model which yielded the creation of a pool of 169 TRW problems. The first two phases of the model included extracting authentic problems from the work of tech engineers and simplifying them to be meaningful or perceivable to students. These were explored by conducting task-oriented interviews with senior tech engineers and scientists from leading companies and universities. The third phase was accomplished by interviewing mathematics education experts, and included verifying the compatibility of the problems with the formal, secondary-level mathematics curriculum. The study has methodological, theoretical, and practical contributions. These include methodology that enables identifying TRW problems that are compliant with the secondary mathematics curriculum; adding to the literature about mathematical modeling by demonstrating the interface between workplace mathematics and school mathematics; and creating a large pool of TRW problems that can be used in secondary school math lessons.
\end{abstract}

Keywords Mathematical modeling $\cdot$ Real-world problems $\cdot$ School mathematics $\cdot$ Workplace mathematics

Zehavit Kohen

zehavitk@technion.ac.il

1 The Faculty of Education in Science and Technology, Technion, Israel Institute of Technology, 3200003 Haifa, Israel 


\section{Introduction}

The growing demand for engineers and scientists in Science, Technology, Engineering, and Mathematics (STEM) domains poses a challenge for the educational system, which is expected to prepare qualified students in these fields (Damlamian, Rodrigues, \& Sträßer, 2013). Mathematics is considered an underpinning discipline for many other sciences, and provides a means for solving problems taken from real-world situations and daily activities of modern society (Blum \& Niss, 1991; Li, 2013; Maaß, O’Meara, O’Donoghue, \& Johnson, 2018). Although a wide range of situations, contexts, and real-world problems can be resolved with the help of mathematics (Common Core State Standards Initiative, 2010), many students do not always see the necessity, application, or relevance of mathematics to the STEM fields or to their everyday lives (Kaiser, Blum, Borromeo Ferri, \& Stillman, 2011). Therefore, students often question why they need to study mathematics at all, which results in low motivation, particularly in secondary school (Schukajlow, Rakoczy, \& Pekrun, 2017). Another concern for mathematics educators that has to do with lack of relevance is the inadequacy of traditional learning methods to engage students in applied problem-solving (Sierpinska, 1995; Wu \& Adams, 2006).

These reasons have driven mathematics educators, international policymakers, and various initiatives over the last two decades to explore the usage of authentic problems that reflect the applied nature of mathematics as it is used in daily situations and in other professions (OECD, 2019; Schukajlow, Kaiser, \& Stillman, 2018; The Common Core State Standards Initiative, 2010). In this study, we focus on mathematical modeling as applied problem-solving that requires real-world context, since it is considered an indispensable and important path for moving mathematics toward application (Kaiser \& Sriraman, 2006; Li, 2013). Mathematical modeling refers to the process of building a mathematical model for solving real-world problems (Blum \& Leiss, 2007; Blum \& Niss, 1991; Kaiser \& Sriraman, 2006). Researchers have recently embraced a new paradigm of mathematical modeling implementation that proposes the incorporation of traditional problem-solving within a broader range of interdisciplinary vocational or professional outcomes (Bakker, 2014; FitzSimons \& Boistrup, 2017; Sokolowski, 2018). Specifically, researchers (e.g., Maaß, Geiger, Romero-Ariza, \& Goos, 2019) argue that the use of mathematical modeling can advance students' understanding about the role of mathematics within the STEM fields. Exposing students to the mathematics behind authentic problems taken from actual workplaces, namely workplace mathematics, has the potential to improve their understanding of real-world situations from a mathematical perspective. Use of these problems in school mathematics is valuable to students not just intellectually but also as a convincing and motivating answer as to why study mathematics (Hernandez-Martinez \& Vos, 2018). Furthermore, the ability to understand why mathematics is important for the STEM fields makes these fields more accessible to students, who might choose them for their future studies or careers (Damlamian et al., 2013; Kaiser, van der Kooij, \& Wake, 2013).

Many studies on the significance of using realistic mathematical modeling to improve students' applied problem-solving skills have been conducted over the years (e.g., Freudenthal, 1968; Lesh, 1981; Sevinc \& Lesh, 2018), yet these problems were mostly advocated for their potential rather than for clear evidence of their ability to motivate and engage students, particularly during formal lessons (Beswick, 2011; Lesh \& Doerr, 2003; Liljedahl, Santos-Trigo, Malaspina, Pinkernell, \& Vivier, 2017). In the 
formal school setting, the most common method for use of problems of an applicative nature is word problems found in textbooks that simplify decontextualized real-life scenarios, which in most cases are not connected to students' lives and thus are not meaningful to them (Palm, 2007; Wyndhamn \& Säljö, 1997). Moreover, applications of authentic, real-world mathematics that reflect problems addressed in tech workplaces or the STEM industry have hardly been documented in previous studies (Damlamian et al., 2013; Kaiser, van der Kooij, \& Wake, 2013). Substantial research is needed to explore the use of mathematical modeling as an educational interface between workplace mathematics, particularly tech-related real-world (TRW) problems, and formal school mathematics, particularly in secondary school.

The goals of this study are threefold: first, to identify TRW problems that can be addressed using mathematical modeling at the secondary school level; ${ }^{1}$ second, to explore the methods engineers use to simplify such problems for non-experts in their field; and third, to investigate the compatibility of the identified TRW problems with the existing secondary mathematics curriculum.

\section{Theoretical framework}

\subsection{Mathematical modeling}

In mathematical modeling, students elicit a mathematical solution for a problem that is formulated in mathematical terms but is embedded within meaningful, real-world context (Damlamian et al., 2013). Mathematical modeling is defined as a cyclic process that involves the transition from a real-life situation to a mathematical problem. Researchers have described various approaches for constructing the modeling cycle (e.g., Borromeo Ferri, 2006; Blum \& Niss, 1991; Doerr \& English, 2003; Galbraith, Renshaw, Goos, \& Geiger, 2003; Lesh \& Doerr, 2003; Niss, Blum, \& Galbraith, 2007). In this study, we chose to focus on the model suggested by Blum and Leiss (2007) (see Fig. 1).

Figure 1 demonstrates the seven main phases of the mathematical modeling cyclic process: (1) understanding a real-world situation; (2) simplifying (idealizing) the real-world situation to obtain a real-world model; (3) mathematizing the real-world model, i.e., devising a plan for solving the problem by translating the real-world model into a mathematical model; (4) applying mathematical routines and processes; (5) interpreting the mathematical solution by verifying that the problem accords with reality; (6) validating the results of the previous stage, i.e., checking the adequacy of the results and repeating certain stages or even the entire modeling process if necessary; and (7) presenting the results of the modeling cycle.

The first two phases are included in the reality realm, which is outside the scope of mathematics (extra-mathematical domains). In this study, the real-world context is obtained from authentic workplace situations. In order to investigate the transition from a real-world workplace situation to the mathematics realm in the context of school mathematics, we present the following literature about the interface between workplace mathematics and school mathematics.

\footnotetext{
${ }^{1}$ We refer to secondary school level as it is defined in Israel, where this study was situated, i.e., students in the tenth to twelfth grades, aged 15-18.
} 


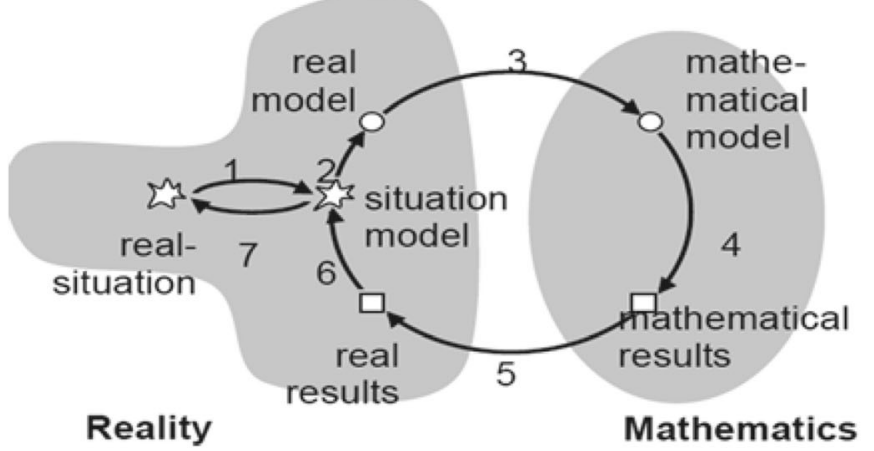

1 understanding the task

2 simplifiying/ structuring

3 mathematizing

4 working mathematically

5 interpretation

6 validation

7 presenting

Fig. 1 The modeling cycle (Blum \& Leiss, 2007)

\subsection{The interface between workplace mathematics and school mathematics}

Workplace mathematics and school mathematics are different fields (FitzSimons, 2013). Workplace mathematics is the contextual, functional calculations necessary for concrete work activities, while school mathematics is often more abstract (Kaiser, van der Kooij, \& Wake, 2013). FitzSimons and Boistrup (2017) identified four types of mathematics used in vocational or professional education, of which the types on either end of the spectrum do not reflect the nature of workplace mathematics. Type A refers to "context-free," decontextualized mathematics, and type D is "mathematics free," referring to vocational activities that are apparently unrelated to mathematics. The intersection between type B-explicit use of mathematical models before, during and following work activities, and type $\mathrm{C}$-mathematical concepts and methods implicitly integrated into work activities (ibid, p. 344), represents how mathematics is contextualized in the workplace.

Workplace mathematics is more visible to experts in the field than to the lay public, yet as computers take over a growing number of mathematical tasks and most calculations are performed almost automatically, mathematics is often packaged into a "black box" so that even those working on the problem may not realize it is there (Damlamian et al., 2013; Williams \& Wake, 2007). Understanding the mathematics behind solutions for workplace problems becomes important when creative solutions are needed, such as for groundbreaking applications that lead to important breakthroughs (Gravemeijer, 2013; Levy \& Murnane, 2007). The skills needed for workplace mathematics have been described in previous studies (Hoyles, Noss, Kent, \& Bakker, 2013; van der Wal, Bakker, \& Drijvers, 2017), which identified seven types of skills called techno-mathematical literacies, referring to skills such as data literacy, technical communication skills, and technical creativity.

Concerning school mathematics, researchers differentiate between common methods used to expose students to the applied nature of mathematics, ranging from the simplest to the most complicated: (1) simple word problems, (2) formulation of mathematical tasks in lay language, (3) illustration of mathematical concepts, such as printed diagrams or body gestures, (4) application of well-known mathematical algorithms, such as trial and error, for solving realworld problems, and (5) modeling, which refers to the use of complex problem-solving processes (FitzSimons \& Boistrup, 2017; Maßß, 2006).

Technological advancements have increased the prevalence of mathematics in the workplace (OECD, 2019), thus creating more opportunities for interfaces between workplace 
mathematics and school mathematics, yet effective interfacing requires the support of all stakeholders. From the school mathematics perspective, teachers should better prepare students to confront real-world situations in modern life by enhancing their understanding of workplace mathematics, which is unlike most "realistic" and "authentic" problems that students encounter in formal school mathematics (FitzSimons \& Mitsui, 2013; Hahn, 2014). Incorporating these learning experiences can offer students the opportunity to make sense of the practices that engineers use (FitzSimons, 2013). From the industry perspective, engineers and other employees should understand the complexity of workplace mathematics and be able to communicate the professional terms and the underlying mathematics using clear and concise explanations in plain language that can be understood by non-experts (Garfunkel, Jeltsch, \& Nigam, 2013), yet the most common method used for presenting real-world problems in formal secondary school settings is word problems, which wrap purely mathematical problems into a verbal description of out-of-school scenarios and other disciplines (Depaepe, De Corte, \& Verschaffel, 2010). For instructional purposes, these problems often present a distorted picture of reality, or provide minimal extra-mathematical information with limited applicability (Blum \& Niss, 1991), causing students to often ignore the relevant real-world aspect. Therefore, these problems do not prepare students for the transition to specific mathematics-related knowledge or for the general problem-solving techniques utilized in workplace activities, especially in rapidly changing technology environments (Beswick, 2011; Bonotto, 2013; Hoogland, Pepin, de Koning, Bakker, \& Gravemeijer, 2018). In this study, we suggest the use of mathematical modeling to create an educational interface between workplace mathematics and school mathematics.

\subsection{Mathematical modeling as an interface between workplace mathematics and school mathematics}

This study builds upon the modeling model suggested by Blum and Leiss (2007), using workplace mathematics as the context for TRW problems within the reality realm, and formal secondary school mathematics as the context for defining the mathematics realm. The transition between these two contexts reflects the mathematical modeling cycle (see Fig. 2).

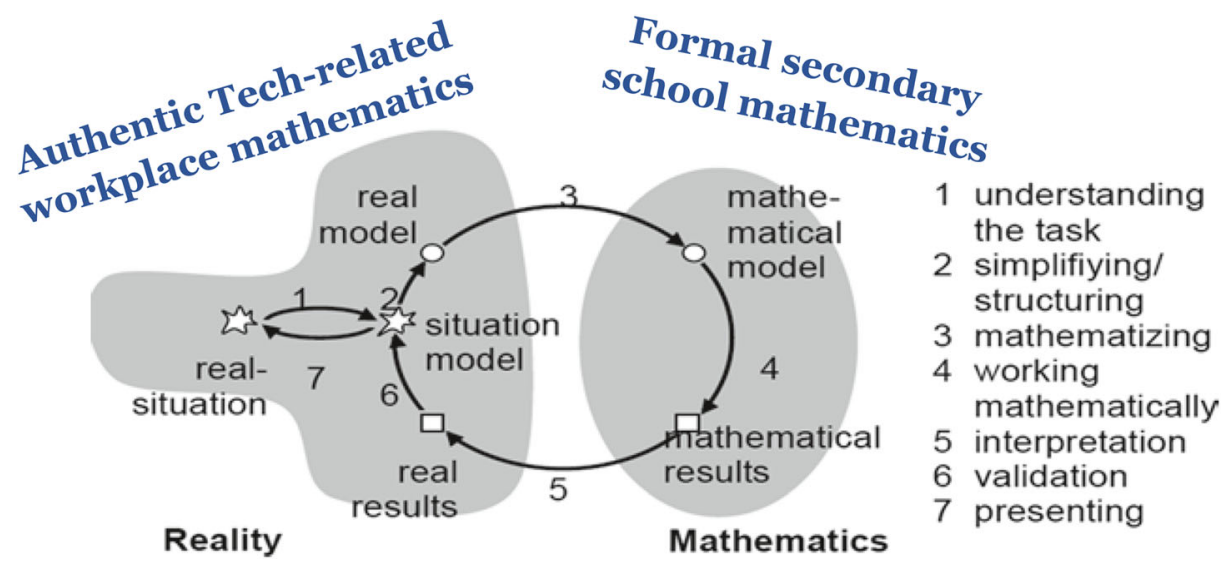

Fig. 2 The research model for mathematical modeling as an interface between workplace mathematics and school mathematics, based on Blum and Leiss' (2007) modeling cycle 
Researchers emphasize the extreme significance of the first two phases of the modeling cycle, which reflect the transition from a real-world situation to the situation model within the reality realm (Blum, Galbraith, Henn, \& Niss, 2006; Blum \& Leiss, 2007). This study emphasizes both phases, namely understanding the real-world situation and simplifying it. As this study focuses on TRW problems from authentic real-world situations, our goal was to identify the tech domains in which such problems can be found, and determine how to simplify them without compromising the authenticity of the original problem. Authentic real-world problems, in this sense, are problems that are slightly simplified so that people who work in the field can recognize them as problems they may encounter in their daily work (Kramarski, Mevarech, \& Arami, 2002; Niss, 1992).

We went on to look at the completion of the modeling cycle by implementing the interface with the mathematics realm, and depicting a process of identifying and classifying TRW problems that might be suitable for the formal secondary school mathematics curriculum. This involved a process of "educational modeling" that is usually carried out by educational designers, teachers, educational researchers, or curriculum developers (Kaiser \& Sriraman, 2006). This perspective of modeling is distinguished from "student mathematical modeling," namely the modeling cycle that students encounter as learners in school, which is outside the scope of this study.

There is a consensus among researchers and policymakers about the relevance of modeling to school mathematics. Authentic modeling problems can be implemented in formal lessons mostly via long-term, extensive, and complex projects, unlike short-term modeling activities during which students solve considerably simpler problems in one or two lessons (Blum \& Niss, 1991; Kaiser, Bracke, Göttlich, \& Kaland, 2013). For example, a study presented by Bonotto (2013) at the ICMI-ICIAM study group described a project conducted in Italy that involved a partnership between school, industry, and university. In this project, secondary school students worked on industrial problems, while workplace managers visited schools to scaffold students in the modeling process using programming, statistics, etc.

The current study aims to present a methodology for educational mathematical modeling by extracting authentic problems from the work of tech engineers, simplifying them to be meaningful to students, and mapping the results of the modeling cycle to suit the formal mathematics curriculum. Therefore, the research questions are:

1. In which tech domains can real-world problems be identified that can be addressed using mathematical modeling for the secondary school level?

2. Which methods do engineers use to simplify tech-related problems for non-experts in their field?

3. In which areas in the secondary mathematics curriculum can TRW problems be mapped?

\section{Methodology}

The study was conducted in three phases. The first addresses phase 1 of the modeling cycle, and identifies tech-related domains from which mathematical problems can be retrieved that can potentially be solved using mathematics from the secondary school curriculum. These were used to create a preliminary pool of TRW problems. The second addresses phase 2 of the modeling cycle, and explores engineers' views regarding methods for simplifying TRW problems for non-experts, particularly secondary school mathematics teachers and students. 
Phase 3 involves transitioning to the mathematics realm and completing the modeling cycle for mapping TRW problems into various mathematical subjects based on the Israeli secondary mathematics curriculum.

\subsection{Participants, tools, and procedure}

Phase 1 was conducted over a period of 3 years and included task-oriented interviews with 27 senior engineers from seven leading Israeli tech companies (five females; age range: 31-64). The participants volunteered to take part in the study based on their personal acquaintance with the second author. Inclusion criteria were as follows: (a) very rich working experience in the tech industry (over 20 years in most cases); (b) involvement in successful projects that ultimately hit the market, such as providing significant breakthroughs on national or international scales; and (c) a field of expertise that is tied directly to the mainstream business of the company they work in.

Task-oriented interviews were used for collecting data, due to reasonable collection time using this method (compared to ethnographic observations, for example), and due to the validity of this method for this study, which aimed at identifying the mathematics used in specific technological tasks or practices. In some of the companies, particularly those working on an innovative patent, there were restrictions related to intellectual property rights and secrecy that prevented us from obtaining data directly from the engineers. In these cases, data was retrieved indirectly by our participants, who provided published articles and patents in their field of expertise. Another source of information was the personal work experience of the second author, who served as a senior engineer at a tech company in Israel for about 30 years. The interviews, each 1.5-2 h, were conducted at the workplaces of the engineers, and were audio recorded. Each interview began by asking the engineers to describe tasks and practices at their workplace that involve the use of mathematics at the secondary school level. Many of the engineers had trouble describing such tasks and practices; thus as a prompt, we presented them with an example of a TRW problem. One of the problems presented to the interviewees was the YouTube problem [taken from the media technology domain]. The interviewees were shown Fig. 3, which presents a YouTube video display. The interviewer explained how this problem relates to the classical mathematics pool problem (a typical algebra word problem used in the secondary mathematics curriculum) as follows: while watching YouTube, we can observe two indicators - video loading (analogous to filling a pool with water) and video viewing (analogous to emptying the pool). The time between the start of loading and the start of viewing is called latency. The question addressed by engineers is how direct and continuous streaming can be guaranteed. The mathematical solution that underlies this situation is based on calculating the optimal latency using an algebraic calculation, to try to ensure that the video will run smoothly. For example, given a video that is $5 \mathrm{~min}$ long and uploading of the video (from the beginning) takes $6 \mathrm{~min}$, what is the shortest possible latency that can guarantee continuous streaming? To achieve this goal, the uploading rate at a given time $(t)+$ latency time $(x)$ must be greater than the rate of viewing at the same time, that is $\frac{5}{6} \cdot(t)+x>1 \cdot t$. This leads to the solution that the latency time must be greater than $\frac{1}{6}$ of the video length $(t)$.

The structure of the task-oriented interview was designed based on literature that deals with applied mathematics in STEM-related fields (e.g., Hoyles et al., 2013; Van der Wal et al., 2017), and included questions about the engineers' tasks and practices at work, and more specifically about projects or tasks that might be interesting, relevant, and meaningful to 


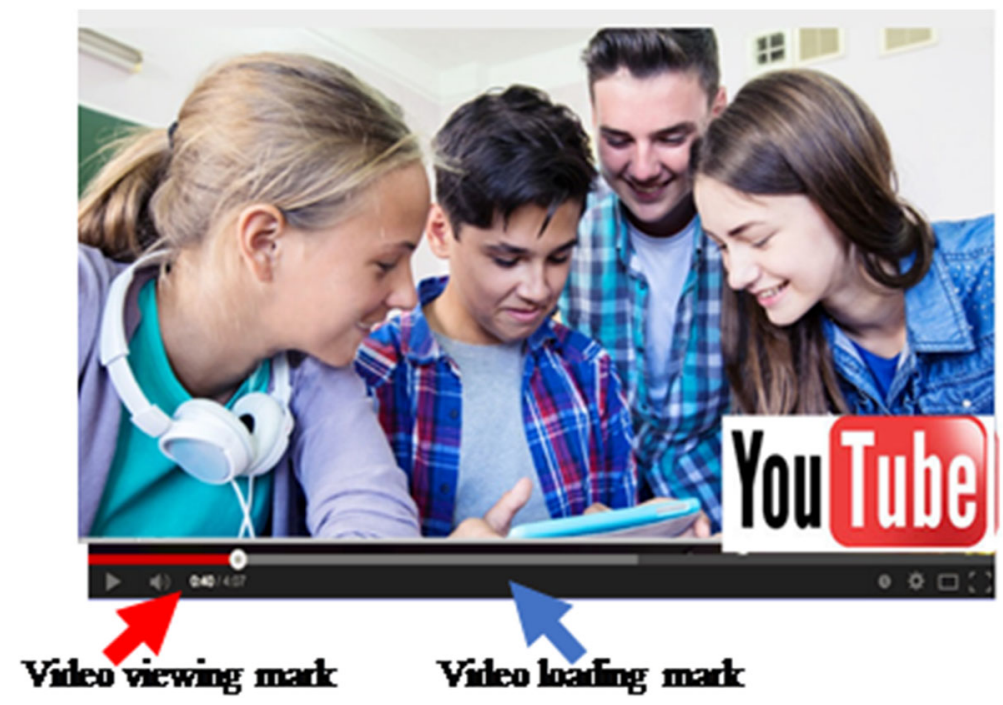

Fig. 3 Illustration of a TRW problem, taken from the work of tech engineers

secondary school students. For example, "Please describe one of your (or one of your colleagues') current or past projects. How does it involve the use of mathematics problemsolving processes?", or "How does mathematics problem-solving impact your tasks or practices at work as an engineer?". We then encouraged the interviewees to think of projects that might be interesting and inspiring for secondary school students, though not too complicated. Our goal was to find problems that are interesting and relevant to secondary-school students by asking the tech professionals to describe a significant breakthrough they experienced or discovered in their workplace, or a task or practice that teachers or students are exposed to directly as technology users (such as smart-phone, GPS, etc.) or indirectly (e.g., success stories in the media). In order for these problems to be understandable to secondary school students, we asked the participants to describe a task or practice that they believe can be solved by a mathematical model that can be understood by secondary school students.

Phase 2 of the study attempted to validate that the real-world aspect of the TRW problems collected in the previous phase can be simplified so that secondary school teachers and students without expertise in the STEM field from which they were extracted can understand them. This phase included structured interviews with six senior engineers of the 27 engineers who participated in this study. The engineers received a very brief description of each of the problems found in phase 1 , and were asked whether these problems could be simplified for non-experts in tech or engineering fields, particularly teachers and students. Based on their personal experience, the engineers were then asked to specify how they recommended presenting each problem to secondary school teachers and students. Those who were unfamiliar with the population of teachers and students were asked to think of other non-experts: "What are the main methods you use to present a task or project you are working on to nonexperts, such as journalists or marketing people, or to your manager?", or "Please describe a task or practice in your work in a simple, but interesting or inspiring way". Problems that were determined to be too complicated to simplify for non-experts in STEM fields were removed from the pool. 


\section{PHASE 1}

Creating a preliminary pool of TRW problems by identifying tech-related problems

with potential to be solved with mathematics within the bounds of the secondary school curriculum

\section{PHASE 2}

Simplifying the real-world aspect of the TRW problems

\section{PHASE 3}

Completion of an educational modelling process and mapping the TRW problems to the secondary mathematics curriculm

\section{A final pool of TRW problems}

Fig. 4 Visualization of the process employed for this study

Once a pool of TRW problems was created in phase 1 and the problems were found adequately simplified in phase 2 , we began phase 3 of the study in which the authors of this paper and three mathematics education experts, of whom two serve as policymakers in the Israeli educational system, completed the educational mathematical modeling cycle. This involved mathematization of the real-world model, applying mathematical routines and processes to solve the TRW problem using mathematics, and interpreting and validating the mathematical solution based on how it accords with reality. Each TRW problem was then mapped to specific fields in the secondary mathematics curriculum. After reviewing the official Israeli mathematics curriculum for secondary schools and studying several popular resources, including two of the most popular textbooks in Israel and web-based teaching materials, ${ }^{2}$ we created a dataset of problems. Problems that did not suit the Israeli secondary school curriculum were eliminated.

See Fig. 4 for a visualization of the process used to create the pool of TRW problems for this study.

\subsection{Data analysis}

We applied qualitative content analysis to code the data retrieved from the task-oriented interviews conducted in phase 1, and identify categories that can be flexibly drawn from it (Cho \& Lee, 2014). We analyzed transcripts of the interviews and created a list of categories with provisional names. In phase 1, categories were defined by grouping families of tech-

\footnotetext{
2 (1) The National Center for Math Teachers in Secondary Education: http://newhighmath.haifa.ac.il; (2) The Ministry of Education's Etgar 5 project: https:/ebagcourses.cet.ac.il/\%D7\%94\%D7\%90\%D7\%AA\%D7\%92\% D7\%A85/ [in Hebrew]
} 
related applications into main domains. For example, real-world applications such as GPS, sound-ranging, doppler radars, camera-based measurements, and laser-based measurements were included in the "measurements" domain. After consulting with experts in each of the tech-related fields, we validated the coding process by making sure that the category name was representative of the TRW problems that were assigned to it, and if not, we refined the name. We also validated the description of each category to verify its accuracy. This process produced the following eight categories: numerical analysis, machine learning, mechanical engineering, digital communication, signal processing, microprocessor design, graphics, and measurements (description of each category appears in the Findings section).

In phase 2 of the study, we applied directed content analysis (Hsieh \& Shannon, 2005). For each interview transcript, we created a list of categories based on distinctions in the literature about methods used to expose students to the applied nature of mathematics (FitzSimons \& Boistrup, 2017; Maßß, 2006). This process produced three main categories of what engineers considered effective methods for simplifying the TRW problems for non-experts in their fields, particularly secondary school mathematics teachers and students. Interrater reliability was measured for both phases based on Cohen's kappa, and ranged between 0.88 and 0.90 , suggesting a reliable coding procedure.

Categories for phase 3 were defined by the various topics included in the secondary school mathematics curriculum: calculus, geometry, word problems, trigonometry, series, analytical geometry, and probability. These are transverse subjects covered in various study levels, according to the secondary school mathematics curriculum defined by the Ministry of Education in Israel. They also represent curriculum subjects that are based on previous topics that are taught starting from middle school and throughout high school.

After defining the categories for each of the three phases described above, we calculated frequencies for each category, i.e., the number of instances of each repeated category. This provided an indication of the fields in the tech industry that can contribute more TRW problems (in response to the first research question); the most common method for simplifying the TRW problems, in the engineers' opinions (in response to the second research question); and the topics in the secondary mathematics curriculum for which the TRW problems can most likely be adjusted (in response to the third research question).

\section{Findings and discussion}

Regarding the first research question, we strived to identify domains in the tech industry from which we can extract TRW problems that can be solved using mathematical models at the secondary school level. When we first presented the question, most participants responded that they do not apply mathematical problem solving in their daily work, since they use tools that embed the mathematics. For example, a design engineer responded that "You don't need to solve partial differential equations to simulate circuit behavior: a circuit simulator is just doing it for you!'. Indeed, as shown in previous studies, engineers and STEM professionals tend not to acknowledge the mathematical aspects of their work, and see them as a "black box" (van der Wal et al., 2017), yet our methodology of task-oriented interviews enabled us to create a pool of 250 TRW problems. Table 1 presents the full description of each of the various tech areas that contributed TRW problems for this study, including examples.

Figure 5 presents the different domains in which we found relevant problems and the frequency of problems within each domain. 
Table 1 The various tech domains that contributed TRW problems for this study: descriptions and examples

\begin{tabular}{|c|c|c|}
\hline Tech field & Description & Examples for TRW problems \\
\hline Measurements & $\begin{array}{l}\text { Mathematical algorithms for solving complex } \\
\text { problems related to measuring distances, } \\
\text { velocity, and location in various ranges. }\end{array}$ & $\begin{array}{l}\text { Used in stereo-based measurements for close } \\
\text { objects, motion-based implementations, } \\
\text { and radar that detects radio waves to de- } \\
\text { termine the range, angle, or velocity of } \\
\text { objects. A specific example is the haversine } \\
\text { formula, used for navigation. The formula } \\
\text { determines the great-circle distance be- } \\
\text { tween two points on a sphere, given their } \\
\text { longitudes and latitudes. }\end{array}$ \\
\hline Graphics & $\begin{array}{l}\text { A field in computer sciences that uses } \\
\text { advanced mathematic knowledge and } \\
\text { hardware solutions for 2D and 3D imaging. }\end{array}$ & $\begin{array}{l}\text { One example is ray-tracing in computer } \\
\text { games. Ray-tracing is a technique used to } \\
\text { compute visibility between points. Light } \\
\text { transport algorithms are designed to simu- } \\
\text { late the way light propagates through space } \\
\text { (while interacting with objects). They are } \\
\text { used (in short) to compute the color of a } \\
\text { point in the scene. }\end{array}$ \\
\hline $\begin{array}{l}\text { Microprocessor } \\
\text { design }\end{array}$ & $\begin{array}{l}\text { The field of electronic engineering used to } \\
\text { design computer processors, including } \\
\text { concepts such as multi-core, memory } \\
\text { architecture, and pipeline. }\end{array}$ & $\begin{array}{l}\text { The most basic example is the design and } \\
\text { implementation of combinational logic } \\
\text { circuits. }\end{array}$ \\
\hline
\end{tabular}

Signal
processing

Digital communication

Mechanical engineering

\section{Machine learning}

Numerical analysis
Signal processing focuses on analyzing, modifying, and synthesizing signals such as sound, images, and biological measurements to improve transmission, storage efficiency, and quality. Conversion of analog signals into digital representation is the foundation of any contemporary computer network.

Exchange of data in a digital form. For example, communications done over the internet is a form of digital communication.

This refers to hardware machines, ranging from traditional machineries, such as piston-engine, to advanced robotic arms with software embedded in the hardware.

The area of computer science and artificial intelligence that deals with the development of algorithms designed to allow the computer to learn from examples, and perform a variety of computational tasks. The main stages of a machine learning project include defining the problem, preparing data, evaluating algorithms, and improving and presenting the results.

Use of mathematical algorithms in software for fast and efficient arithmetic computations, such as inverse square root calculations or finding prime numbers.
Used in noise reduction algorithms, or data compression for encoding information. Another example is the basic transformation from analog to digital signals using the Fourier Transform, a mathematical transform that breaks down a function into its constituent frequencies.

Used for encryption or authentication of data. A specific example is detecting data loss during communication.

Calculating how to move a robot arm using inverse calculations, while using rotation and translation matrices that reflect the 3D world.

A typical example of machine learning is the ability of a computer to identify an object like an animal in a new picture it had never analyzed before or to reconstruct a colored picture based on a black and white image.

Computer graphics programs use inverse square roots to compute angles of incidence and reflection for lighting and shading. The fast inverse square root is an algorithm that estimates the reciprocal (or multiplicative inverse) of the square root of a 32-bit floating-point number. 


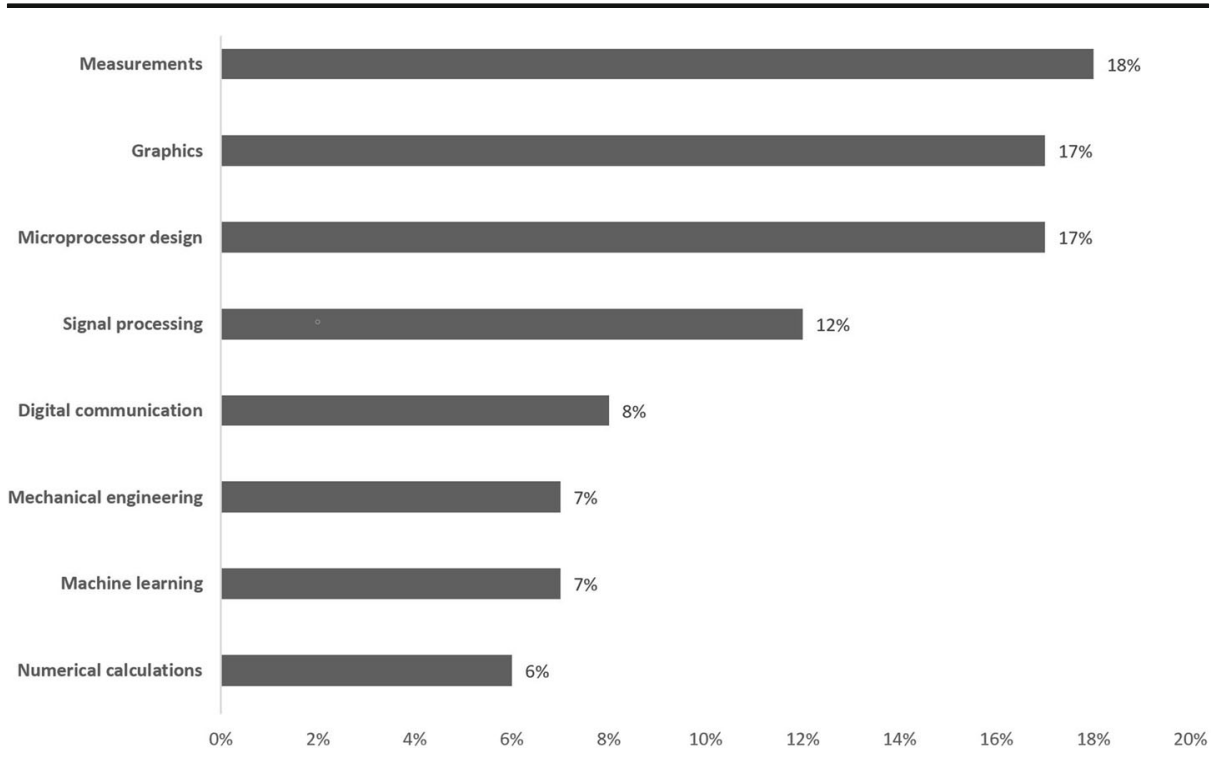

Fig. 5 The distribution of TRW problems $(N=250)$ according to various tech-related fields (in descending order)

According to Fig. 5, about $50 \%$ of the problems were extracted from the measurements, graphics, and microprocessor design domains. In the section below, Illustrative examples, we present examples of TRW problems from the microprocessor design and graphics domains. Another example from the numerical analysis domain, which was the least frequent domain, is presented below. As can be seen in these examples, the mathematical model that should be used for solving the numerical analysis problem is more complicated than the mathematical model used to solve the problems from the microprocessor design and graphics domains. This occurred in other cases as well, leading to our conclusion that the less complicated the interface with the mathematics realm, the more problems were supplied by the engineers in those domains. This finding is interesting since it suggests that the distribution of areas from which TRW problems can be retrieved from various work activities is not dependent on the explicit or implicit nature of workplace mathematics, as defined by FitzSimons and Boistrup (2017), but rather on the content of that domain.

Regarding our second research question, we identified three main methods that engineers consider effective for simplification of TRW problems for secondary school mathematics teachers and students. These categories are (a) bridging analogies, namely explaining the TRW problem using well-known mathematical algorithms that are familiar to teachers and students; (b) representations, i.e., illustrating the TRW problem using simplified pictures or diagrams; and (c) simplified explanations, which communicates the technical information in the TRW problem using simple, lay language.

The most common method, which was deemed appropriate for simplifying about $45 \%$ of the problems, was bridging analogies, i.e., explaining the problem using an analogy that is familiar to the target audience. The second method, which they deemed suitable for about $33 \%$ of the problems, was representation, i.e., illustrating the problem using simplified pictures or diagrams. The final method specified was the use of simplified explanations for about $22 \%$ of the problems. At this stage, about 50 problems were removed from the pool of problems since the engineers could not think of a method that could be used to simplify them for non-experts, 
particularly for teachers and students. The engineers' choice of methods for explaining the professional terms used for workplace mathematics is significant from two perspectives. From the workplace mathematics view, this finding demonstrates the importance of technical communication skills. These skills, which refer to "the ability to communicate technical information with colleagues, customers, supervisors, and other parties" (van der Wal et al., 2017; P. 94), were also found to be prevalent in tech-related workplaces in previous studies (e.g., ibid.; Hoyles et al., 2013). From the school mathematics view, the methods suggested by the engineers for simplification of tech-related problems coincide with common methods used to expose students to the applied nature of mathematics (FitzSimons \& Boistrup, 2017; Maaß, 2006). Simplified explanations, which were found to be effective for communicating the technical information in the TRW problems in lay language, might accord with the formulation of mathematical tasks in lay language. Representations, namely illustrating the TRW problem using simplified pictures or diagrams, accord with illustration of mathematical concepts. Bridging analogies that are used to explain the TRW problems using analogies that are familiar to teachers and students accord with the application of well-known mathematical algorithms for solving real-world problems.

Regarding the third research question, after completing the educational modeling process, we mapped the TRW problems for the Israeli secondary mathematics curriculum. There were cases in which a TRW problem was associated with more than one field in the secondary school curriculum, such as the YouTube problem that was matched to an algebra word problem (see details above in the Methodology section) and to series (such as "If you stream a YouTube video at a constant rate of $x$ kilobytes per second, what is the cumulative number of downloaded kilobytes?...", which is based on calculation of the sum of an arithmetic series). In cases where a problem did not match any field in the secondary curriculum, it was removed from our pool. An example of such a problem is the RSA cryptosystem for public-key encryption, taken from the numerical analysis domain. The engineers presented this TRW problem and its mathematical solution using a simplified explanation that demonstrated a simple case of secure data transmission. However, the mathematical model used in the encryption process is based on Number Theory, which is not part of the Israeli mathematics curriculum for secondary school. Therefore, although this problem presents an interesting technology that is considered a breakthrough, and can be explained to secondary mathematics teachers and students who are non-experts in the numerical analysis field, it was excluded from our pool of problems. Similarly, about 30 other problems were removed from the pool of problems due to their incompatibility with the Israeli mathematics curriculum. In total, our final pool of TRW problems contained 169 problems.

Figure 6 presents the mapping results, in which each row represents a tech domain, while the distribution of curriculum topics that were mapped to a specific tech domain is represented by different colors (based on the legend below), so that the sum of frequencies for each row equals $100 \%$. Note that since some of the TRW problems were matched to more than one field in the secondary school curriculum, we do not present the total number of problems associated with each of the tech-related fields.

Figure 6 shows seven main subjects in the secondary school curriculum that can be used to explain practices that engineers use. The curriculum areas associated with the top three tech domains (i.e., measurements, graphics, and microprocessor design), in which we found about $50 \%$ of the problems, were the most diverse. These findings indicate the multitude of areas in the curriculum that can be presented using TRW problems, offering a practical response to international calls (e.g., OECD, 2019; The 


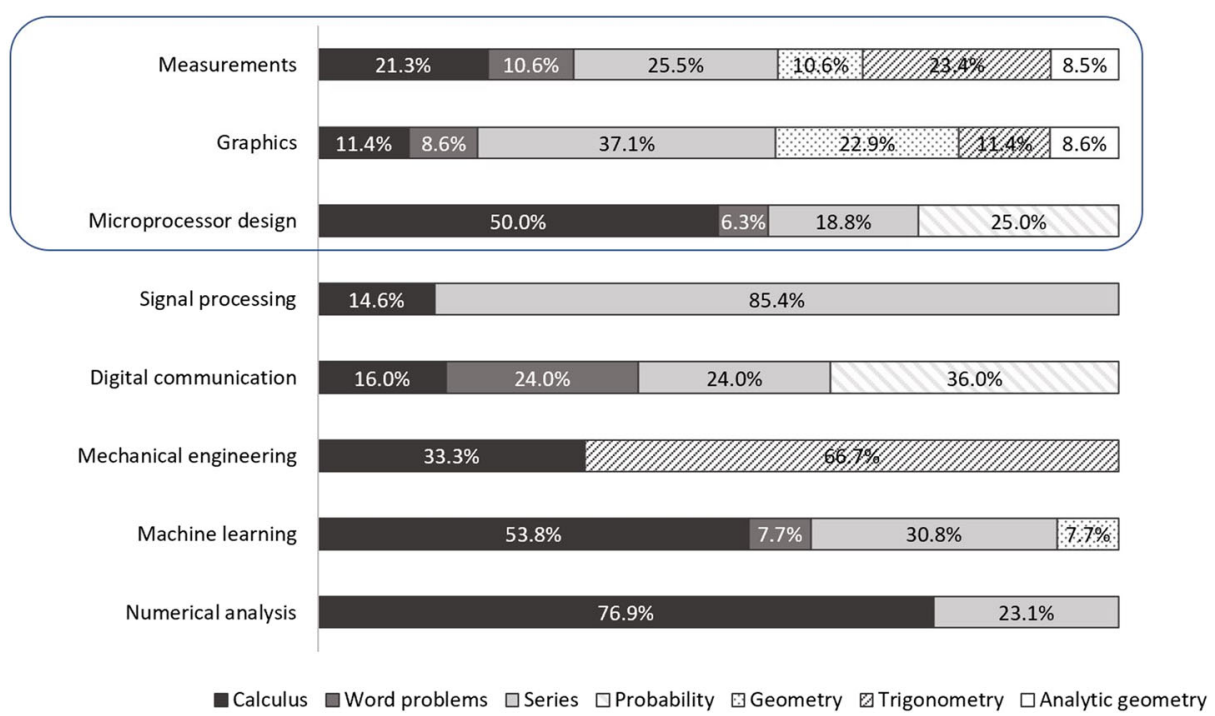

Fig. 6 TRW problems and their relation to secondary school mathematical curriculum

Common Core State Standards Initiative, 2010) to invest efforts in demonstrating the applied nature of mathematics to students. The findings suggest that authentic problems that represent real-world scenarios can be incorporated into areas in school mathematics other than word problems, which our study showed to reflect the applied nature of mathematics to a low extent, contrary to common assumptions (Palm, 2007; Wyndhamn \& Säljö, 1997). Moreover, our study suggests implementation of word problems in the curriculum from an applicative, real-world perspective that does not present a distorted picture of reality nor limited applicability, as typical word problems tend to do (Blum \& Niss, 1991).

According to Fig. 6 above, the most common curriculum areas that are attributed to TRW problems are calculus and series, as they appear in each of the tech domains (excluding mechanical engineering which relates to calculus but not to series). In contrast, geometry and analytic geometry are attributed to only a few tech areas and have low frequencies in the subjects in which they appear, yet this finding should be carefully considered and does not necessarily indicate that the former curriculum areas represent a more applied nature of mathematics, particularly due to our criteria for choosing the companies from which we retrieved TRW problems. Following previous research (e.g., FitzSimons, 2013; Gravemeijer, 2013; Levy \& Murnane, 2007) that highlights the importance of understanding workplace mathematics, specifically when they involve creative solutions, we chose only leading tech companies in the Israeli local industry with applications that are profitable and acclaimed in the global industry. Moreover, we asked the engineers to share only significant, interesting practices or tasks they have encountered, such as breakthroughs on the national or international levels. Thus, there are curriculum areas that are not included in our study, either because the tech "story" behind their application is not interesting enough for students or other stakeholders; the complexity of their application in tech companies exceeds secondary school level, such as use of complex numbers at a high-level; or they lack an applicative nature, for example problems that are solved using calculations of the diagonal meeting 
point in a kite. The methodology presented in this study allowed us to filter out the problems that are unsuitable for the main reasons mentioned above, yet since we were obviously unable to retrieve all the possible tech-related real-world problems, we cannot guarantee that a problem that is not included in our pool is non-applicative in nature or that there are no workplace tasks or practices that support its applicability.

\subsection{Illustrative examples}

Following are two examples of TRW problems that can be simplified using the most common methods suggested by the engineers, i.e., bridging analogy and representation. Each problem is presented in a way that demonstrates the educational mathematical modeling process that can be used to solve the authentic real-world problem, from simplification of the TRW problem, to the mathematization and application of the problem, to the formulation of a mathematical solution. We do not elaborate on the final phases of interpretation and validation of the mathematical solution.

Bridging analogies The following example was extracted from the microprocessor design domain and demonstrates a technology called "Triple Modular Redundancy" (TMR) in which instead of one system performing a process, three systems run in parallel and are processed by a majority-voting system to produce a single output. This technology is commonly used in aviation, car controllers, electronic component design, fault tolerance in memory, and disk arrays. A TRW problem related to spaceships was presented by the engineers to exemplify the use of TMR technology, while justifying use of probability as the proper mathematical model for solving this problem. To simplify their explanation, an equivalent analogy to the TRW problem was given by the engineers, as presented in Table 2 .

Representations The following example was extracted from the graphics domain and refers to drawing a picture on a computer screen using pixels, which are dots that fill in a digital image. The tech-related problem is based on use of graphic processors to fill a rectangle drawn on the screen with colors. To simplify the TRW problem, the engineers suggested explaining the real-world aspect using the following representation to illustrate the technology behind the problem:

We will use a range of monochrome colors represented by a number between zero (black) and one (white). Given a rectangle and four colors that need to be in each vertex (as shown in Fig. 7a), engineers address the question of how to color each pixel in the rectangle so that the color changes will look smooth (as shown in Fig. 7b).

We will use a technology called "bilinear interpolation," which divides the rectangle into many small rectangles and colors each one of them with small, linear increments from the color of the adjacent rectangles. When using small, linear increments, our eyes will not observe the color jumps. In Fig. 7a, we can more easily observe the color changes, compared to Fig. 7b. The question is how to color each small rectangle? The math modeling is based on an arithmetic series. When translating pixel colors into numbers, smooth pixel changes can be modeled and calculated using the standard arithmetic series equation: $a_{n}=a_{1}+(n-1) * d$. Using this equation, we can first calculate the color of the bottom and top rows. Then, we will fill the other pixels by forming more arithmetic series. 
Table 2 An example TRW problem and its analogy to students' lives

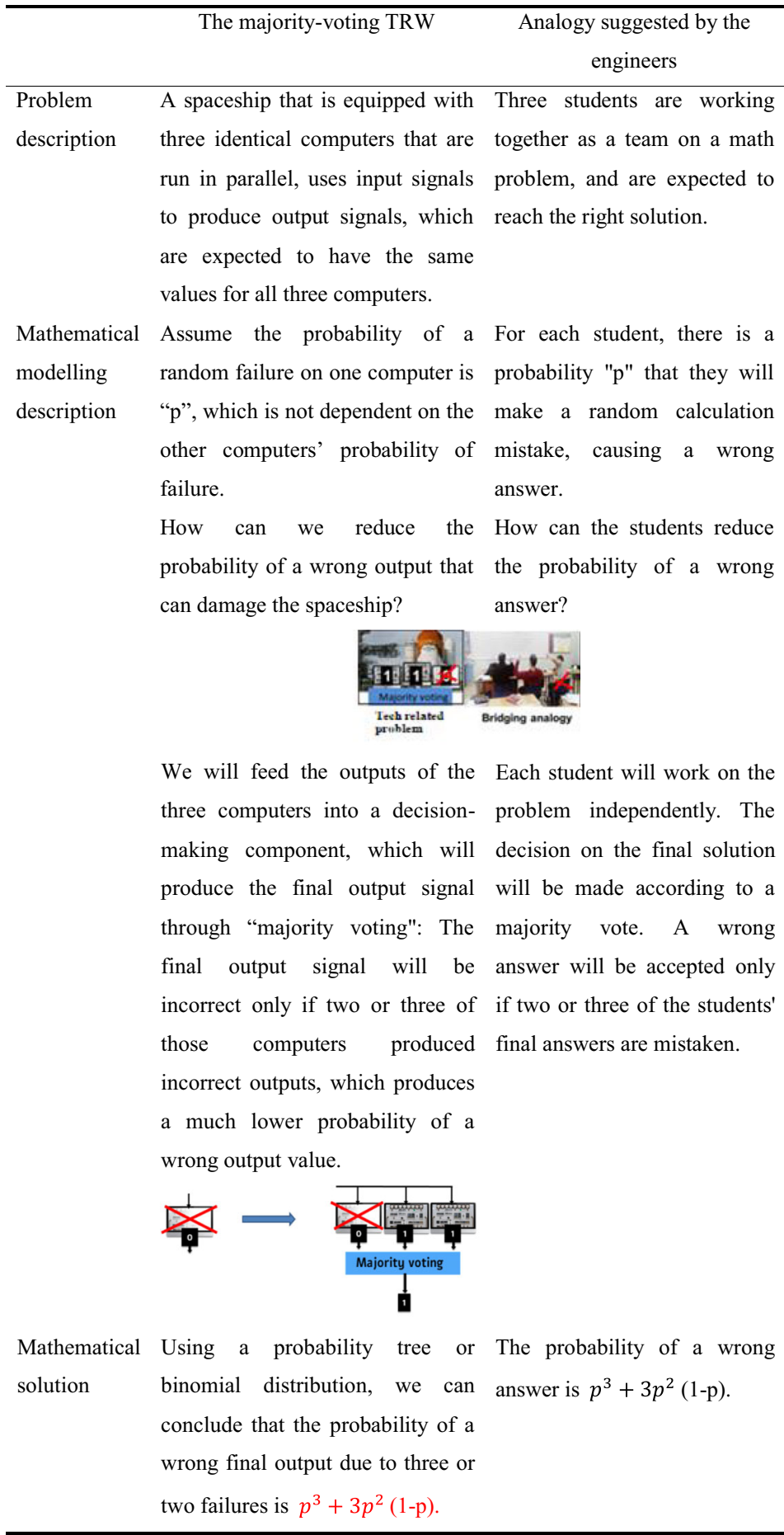




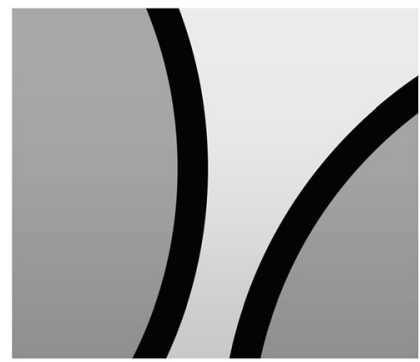

a

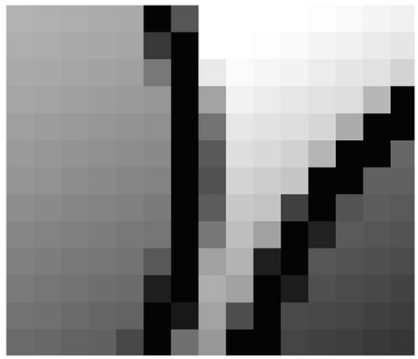

b

Fig. 7 Illustration of two ways of reconstructing an image from a set of pixel values: low resolution (Fig. 7a) and high resolution (Fig. $7 b$ )

\section{Conclusions and contribution}

The current study presents a perspective of mathematical modeling as an educational interface between tech workplace mathematics and formal secondary school mathematics. We present a methodology that follows the mathematical modeling cycle suggested by Blum and Leiss (2007) for identifying tech-related real-world (TRW) problems, simplifying the real-world aspect of the problem, and mapping the problems for the formal secondary school mathematics curriculum after completing the educational modeling cycle process by implementing the interface to the mathematics realm. Following research that emphasized the significance of the first two phases of the modeling cycles (e.g., Blum et al., 2006; Blum \& Leiss, 2007), and following the unique real-world context of the tech-related workplaces included in this study, our research model puts great emphasis on the reality realm of mathematical modeling and on the transition from real-world situations to the situation model that produces the interface with the mathematics realm. In accordance with the first goal of this study, one major finding was that in tech-related domains, the less complicated the interface to the mathematics realm, the more problems the engineers interviewed for this study were able to provide. About $50 \%$ of the problems were extracted from the measurements, graphics, and microprocessor design domains, which constitute three out of the eight main tech domains explored in this study. However, this study does not profess to cover the full range of all possible relevant domains in the tech industry and academy and how they relate to the secondary mathematics curriculum, as the study participants are not a representative sample of the engineering and science world. Our goal was to provide a sense of which domains may be more common across the various STEM fields, and have greater potential to supply problems with underlying mathematical problem-solving processes.

Regarding the second goal of this study, another major finding that also refers to the reality realm of mathematics modeling, was that the most common method specified by the engineers for simplification of TRW problems for secondary school mathematics was bridging analogies. Researchers have emphasized the importance of realism to students' lives for improving their applied problem-solving skills (Freudenthal, 1968; Hahn, 2014; Lesh, 1981; Sevinc \& Lesh, 2018). Engineers suggest using varied methods that they themselves apply to explain the extra-mathematical domain, i.e., the tech-related aspect of the TRW problem. These methods coincide with the common methods used for exposing students to the applied nature of mathematics (FitzSimons \& Boistrup, 2017; Maaß, 2006). We therefore suggest that the 
mathematical modeling process that is manifested in the TRW problem can be explicated using methods that are applicable in school-based settings. Moreover, the feasibility of various methods enables incorporation of these problems into the mathematics curriculum, even if the teacher is not familiar with the technical or professional terms that appear in the problems, thus addressing the growing shift toward mathematical modeling implementation within the formal school system (Bakker, 2014; FitzSimons \& Boistrup, 2017; Sokolowski, 2018).

Regarding the third goal of this study, a major finding is that diverse areas in the formal secondary mathematics curriculum were found to be compatible for demonstrating the applied nature of mathematics, particularly through the connection to tech-related fields. More specifically, we found that the curriculum areas associated with the top three tech domains (i.e., measurements, graphics, and microprocessor design), in which we found about $50 \%$ of the tech-related problems, were the most diverse with respect to their compatibility with the secondary school mathematics curriculum.

We presented two TRW problems that can be simplified using the most common methods suggested by the engineers (see section Illustrative examples). These examples demonstrate our research model, which uses an educational mathematical modeling cycle as an interface between workplace mathematics and school mathematics. The examples of problems given in this study explicate the mathematical modeling process to the student, and demonstrate the process of "educational modeling" that was carried out in this study by mathematics education experts, yet a teacher can use these problems without revealing the solution via the mathematical models, and allow the students to go through the process on their own, i.e., from a "student mathematical modeling" perspective. Bringing TRW problems to the classroom, and demonstrating the mathematical modeling that leads to the solution of the problem, can potentially interest students and improve their motivation to learn mathematics. They can enable teachers to create inspiring lessons that are embedded within the meaningful real-world context, so that students are able to see the necessity, usage, and relevance of mathematics (Kaiser et al., 2011). Moreover, explicating the mathematical modeling process within the TRW problems has the potential to engage students in applied problem-solving during formal mathematics lessons (Wu \& Adams, 2006). Further studies should investigate the effect of using the TRW problems on different factors among both teachers and students, such as teachers' attitudes toward incorporating these problems as part of their ordinary teaching, or students' motivation and success when such problems are implemented in formal lessons. Researchers (e.g., Borromeo Ferri \& Blum, 2010) emphasize the need for mathematics teachers to have vast opportunities to practically engage with mathematical modeling at school. Thus, the connection we made with the formal mathematical curriculum might offer a practical tool for teachers who wish to implement mathematical modeling in their classrooms.

An important contribution of the study is the creation and validation of a pool of 169 realistic and authentic problems that can be solved through the process of mathematical modeling on the secondary school level (examples from this pool can be found at www. imat.org.il). We validated the TRW problems that were identified in this study with engineers using a double validation process, and further validated the compatibility of the TRW problems with the formal secondary school mathematics curriculum with mathematics education experts. The research model of this study has as central role in the process of mathematical modeling as an educational interface between workplace mathematics in the tech industry and school mathematics in formal settings. This interface is also prevalent in the various methods we identified for simplifying the real-world aspects of TRW problems for non-experts, and specifically for secondary school teachers and students. 
The theoretical value of this study is its innovative perspective of the mathematical modeling cycle suggested by Blum and Leiss (2007) as an interface between authentic techrelated workplace mathematics and formal secondary school mathematics. Our contribution to the literature is related to the significance we identify in this study regarding the first two phases of the modeling cycle that occur within the reality realm, namely understanding the real-world situation that is taken from authentic, tech-related workplace mathematics, and simplifying it (Blum et al., 2006; Blum \& Leiss, 2007).

The main contribution of this study is its methodology. We present a methodology that enables the identification of TRW problems, simplifying them using various methods suggested by tech professionals, and verifying their compliance with the secondary mathematics curriculum. Thus, our study suggests a validated methodology for retrieving authentic problems that incorporate mathematics that can be taught on the secondary school level (OECD, 2019; Schukajlow et al., 2018; The Common Core State Standards Initiative, 2010).

The practical contribution of this study lies in the creation of a large pool of TRW problems that can be used in secondary school math lessons and future studies. The underlying assumption of the use of authentic problems in school is that when students are aware of the importance of mathematics and experience its applicability, they may be encouraged to study advanced mathematics, which in turn will influence their opportunities for studies and careers in the STEM fields in the future (Damlamian et al., 2013). The study's practical contribution lies not only in the value of the interface between TRW problems and school mathematics but also in its contribution to the industry, which might recognize the value of mutual interaction with the education sector, not only at the graduate or post-graduate level but also at the secondary level, as these students are the future STEM professionals.

Open Access This article is licensed under a Creative Commons Attribution 4.0 International License, which permits use, sharing, adaptation, distribution and reproduction in any medium or format, as long as you give appropriate credit to the original author(s) and the source, provide a link to the Creative Commons licence, and indicate if changes were made. The images or other third party material in this article are included in the article's Creative Commons licence, unless indicated otherwise in a credit line to the material. If material is not included in the article's Creative Commons licence and your intended use is not permitted by statutory regulation or exceeds the permitted use, you will need to obtain permission directly from the copyright holder. To view a copy of this licence, visit http://creativecommons.org/licenses/by/4.0/.

\section{References}

Bakker, A. (2014). Characterising and developing vocational mathematical knowledge. Educational Studies in Mathematics, 86(2), 151-156.

Beswick, K. (2011). Putting context in context: An examination of the evidence for the benefits of 'contextualised' tasks. International Journal of Science and Mathematics Education, 9(2), 367-390.

Blum, W., Galbraith, P., Henn, H.-W., \& Niss, M. (Eds.). (2006). Applications and modelling in mathematics education. New ICMI studies series no. 10. New York, NY: Springer.

Blum, W., \& Leiss, D. (2007). How do students and teachers deal with mathematical modelling problems? The example "Sugarloaf' and the DISUM Project. In C. Haines, P. L. Galbraith, W. Blum, \& S. Khan (Eds.), Mathematical modelling (ICTMA12)_education, engineering and economics (pp. 222-231). Chichester, UK: Horwood.

Blum, W., \& Niss, M. (1991). Applied mathematical problem solving, modelling, applications, and links to other subjects - state trends and issues in mathematics instruction. Educational Studies in Mathematics, 22, 37-68.

Bonotto, C. (2013). How it is possible to make real-world mathematics more visible: some results from two Italian projects. In A. Damlamian, J. F. Rodrigues, \& R. Sträßer (Eds.), Educational interfaces between mathematics and industry (pp. 109-117). London, UK: Springer. 
Borromeo Ferri, R. (2006). Theoretical and empirical differentiations of phases in the modelling process. ZDMMathematics Education, 38(2), 86-95.

Borromeo Ferri, R., \& Blum, W. (2010). Mathematical modelling in teacher education - experiences from a modelling seminar. In V. Durand-Guerrier, S. SouryLavergne, \& F. Arzarello (Eds.), CERME-6 - proceedings of the sixth congress of the European Society for Research in Mathematics Education (pp. 2046-2055). Lyon, France: NRP.

Cho, J. Y., \& Lee, E. H. (2014). Reducing confusion about grounded theory and qualitative content analysis: Similarities and differences. The Qualitative Report, 19(32), 1-20.

Common Core State Standards Initiative. (2010). Common core state standards for mathematics. Retrieved from http://www.corestandards.org/assets/CCSSI_Math\%20Standards.pdf.

Damlamian, A., Rodrigues, J. F., \& Sträßer, R. (Eds.). (2013). Educational interfaces between mathematics and industry: report on an ICMI-ICIAM-study. New York, NY: Springer.

Depaepe, F., De Corte, E., \& Verschaffel, L. (2010). Teachers' approaches towards word problem solving: Elaborating or restricting the problem context. Teaching and Teacher Education, 26(2), $152-160$.

Doerr, H. M., \& English, L. D. (2003). A modelling perspective on students' mathematical reasoning about data. Journal for Research in Mathematics Education, 34(2), 110-136.

FitzSimons, G., \& Mitsui, T. (2013). Education/training with industry participation. In A. Damlamian, J. F. Rodrigues, \& R. Sträßer (Eds.), Educational interfaces between mathematics and industry (pp. 95-107). London, UK: Springer.

FitzSimons, G. E. (2013). Doing mathematics in the workplace: a brief review of selected literature. Adults Learning Mathematics, 8(1), 7-19.

FitzSimons, G. E., \& Boistrup, L. B. (2017). In the workplace mathematics does not announce itself: towards overcoming the hiatus between mathematics education and work. Educational Studies in Mathematics, 95(3), 329-349.

Freudenthal, H. (1968). Why to teach mathematics so as to be useful. Educational Studies in Mathematics, 1(12), 3-8.

Galbraith, P., Renshaw, P., Goos, M., \& Geiger, V. (2003). Technology-enriched classrooms: Some implications for teaching applications and modelling. In Q. Ye, W. Blum, S. K. Houston, \& Q. Jiang (Eds.), Mathematical modelling in education and culture (pp. 111-125). Chichester, UK: Horwood.

Garfunkel, S., Jeltsch, R., \& Nigam, N. (2013). Communication and Collaboration. In A. Damlamian, J. F. Rodrigues, \& R. Sträßer (Eds.), Educational interfaces between mathematics and industry (pp. 319-332). London, UK: Springer.

Gravemeijer, K. (2013). Mathematics education and the information society. In A. Damlamian, J. F. Rodrigues, \& R. Sträßer (Eds.), Educational interfaces between mathematics and industry (pp. 279-286). London, UK: Springer.

Hahn, C. (2014). Linking academic knowledge and work experience in using statistics, a design experiment for business school students. Educational Studies in Mathematics, 86(2), 239-251.

Hernandez-Martinez, P., \& Vos, P. (2018). "Why do I have to learn this?" A case study on students' experiences of the relevance of mathematical modelling activities. ZDM - Mathematics Education, $50(1-2), 245-257$.

Hoogland, K., Pepin, B., de Koning, J., Bakker, A., \& Gravemeijer, K. (2018). Word problems versus image-rich problems: An analysis of effects of task characteristics on students' performance on contextual mathematics problems. Research in Mathematics Education, 20(1), 37-52.

Hoyles, C., Noss, R., Kent, P., \& Bakker, A. (2013). Mathematics in the workplace: issues and challenges. In A. Damlamian, J. F. Rodrigues, \& R. Sträßer (Eds.), Educational interfaces between mathematics and industry (pp. 43-50). London, UK: Springer.

Hsieh, H. F., \& Shannon, S. E. (2005). Three approaches to qualitative content analysis. Qualitative Health Research, 15(9), 1277-1288.

Kaiser, G., Blum, W., Borromeo Ferri, R., \& Stillman, G. (Eds.). (2011). Trends in teaching and learning of mathematical modelling. New York, NY: Springer.

Kaiser, G., Bracke, M., Göttlich, S., \& Kaland, C. (2013). Authentic complex modelling problems in mathematics education. In A. Damlamian, J. F. Rodrigues, \& R. Strässer (Eds.), Educational interfaces between mathematics and industry (pp. 287-297). London, UK: Springer.

Kaiser, G., \& Sriraman, B. (2006). A global survey of international perspectives on modelling in mathematics education. ZDM - Mathematics Education, 38(3), 302-310.

Kaiser, G., van der Kooij, H., \& Wake, G. (2013). Educational interfaces between mathematics and industry at school level. In A. Damlamian, J. F. Rodrigues, \& R. Strässer (Eds.), Educational interfaces between mathematics and industry (pp. 263-270). London, UK: Springer. 
Kramarski, B., Mevarech, Z. R., \& Arami, M. (2002). The effects of metacognitive instruction on solving mathematical authentic tasks. Educational Studies in Mathematics, 49, 225-250.

Lesh, R. (1981). Applied mathematical problem solving. Educational Studies in Mathematics, 12(2), $235-264$.

Lesh, R., \& Doerr, H. M. (Eds.). (2003). Beyond constructivism: Models and modelling perspectives on mathematics problem solving, learning, and teaching. Mahwah, NJ: Erlbaum.

Levy, F., \& Murnane, R. (2007). How computerized work and globalization shape human skill demands. In M. M. Suárez-Orozco (Ed.), Learning in the global era: International perspectives on globalization and education (pp. 158-174). Los Angeles, CA: University of California Press.

$\mathrm{Li}, \mathrm{T}$. (2013). Mathematical modelling education is the most important educational interface between mathematics and industry. In A. Damlamian, J. F. Rodrigues, \& R. Sträßer (Eds.), Educational interfaces between mathematics and industry (pp. 51-58). London, UK: Springer.

Liljedahl, P., Santos-Trigo, M., Malaspina, U., Pinkernell, G., \& Vivier, L. (2017). Topic study group no. 19: problem solving in mathematics education. In Proceedings of the 13th International Congress on Mathematical Education (pp. 463-466). Cham, Switzerland: Springer.

Maßß, J., O’Meara, N., O’Donoghue, J., \& Johnson, P. (2018). Mathematical modelling for teachers: A practical guide to applicable mathematics education. Dordrecht, the Netherlands: Springer.

Maaß, K. (2006). What are modelling competencies? ZDM-Mathematics Education, 38(2), 113-142.

Maaß, K., Geiger, V., Romero-Ariza, M., \& Goos, M. (2019). The role of mathematics in interdisciplinary STEM education. ZDM - Mathematics Education, 51, 869-884.

Niss, M. (1992). Applications and modelling in school mathematics - directions for future development. Roskilde, Denmark: IMFUFA Roskilde Universitetscenter.

Niss, M., Blum, W., \& Galbraith, P. (2007). Introduction to modelling and applications in mathematics education. In W. Blum, P. L. Galbraith, H. Henn, \& M. Niss, (Eds.), Modelling and applications in mathematics education. The 14th ICMI Study (pp. 3-32). New York, NY: Springer.

Organization for Economic Co-operation and Development. (2019). Education at a Glance 2019. Paris, France: OECD Publishing.

Palm, T. (2007). Features and impact of the authenticity of applied mathematical school tasks. In Modelling and applications in mathematics education (pp. 201-208). Boston, MA: Springer.

Schukajlow, S., Kaiser, G., \& Stillman, G. (2018). Empirical research on teaching and learning of mathematical modelling: a survey on the current state-of-the-art. ZDM-Mathematics Education, 50(1-2), 5-18.

Schukajlow, S., Rakoczy, K., \& Pekrun, R. (2017). Emotions and motivation in mathematics education: Theoretical considerations and empirical contributions. ZDM - Mathematics Education, 49(3), 307-322.

Sevinc, S., \& Lesh, R. (2018). Training mathematics teachers for realistic math problems: A case of modellingbased teacher education courses. ZDM - Mathematics Education, 50(1-2), 301-314.

Sierpinska, A. (1995). Mathematics: In context, pure or with applications? For the Learning of Mathematics, 15(1), 2-15.

Sokolowski, A. (2018). Scientific inquiry in mathematics-theory and practice: A STEM perspective (1st ed.). New York, NY: Springer.

Van der Wal, N. J., Bakker, A., \& Drijvers, P. (2017). Which techno-mathematical literacies are essential for future engineers? International Journal of Science and Mathematics Education, 15(1), 87-104.

Williams, J., \& Wake, G. (2007). Black boxes in workplace mathematics. Educational Studies in Mathematics, 64(3), 317-344.

Wu, M., \& Adams, R. (2006). Modelling mathematics problem solving item responses using a multidimensional IRT model. Mathematics Education Research Journal, 18(2), 93-113.

Wyndhamn, J., \& Säljö, R. (1997). Word problems and mathematical reasoning — a study of children's mastery of reference and meaning in textual realities. Learning and Instruction, 7(4), 361-382.

Publisher's note Springer Nature remains neutral with regard to jurisdictional claims in published maps and institutional affiliations. 